\title{
ILLUMINATING DIVERSITY PRACTICES IN MALAYSIAN HIGHER EDUCATION INSTITUTIONS
}

\author{
Aizan Yaacob ${ }^{1 *}$, Rosna Awang-Hashim ${ }^{1}$, Nena P. Valdez ${ }^{3}$ and Norhafezah Yusof ${ }^{2}$ \\ ${ }^{1}$ School of Education and Modern Languages, Universiti Utara Malaysia, 06010 Sintok, \\ Kedah, Malaysia \\ ${ }^{2}$ School of Multimedia Technology and Communication, Universiti Utara Malaysia, \\ 06010 Sintok, Kedah, Malaysia \\ ${ }^{3}$ Centre for Communication, Teaching and Learning, Universiti Teknologi Brunei, \\ Jalan Tungku Link Gadong BE1410, Brunei Darussalam \\ *Corresponding author: aizan904@uum.edu.my
}

Publication date: 24 December 2019

To cite this article: Aizan Yaacob, Rosna Awang-Hashim, Nena P. Valdez, \& Norhafezah Yusof. (2019). Illuminating diversity practices in Malaysian higher education institutions. Asia Pacific Journal of Educators and Education, 34, 1-16. https://doi.org/10.21315/ apjee2019.34.1

To link to this article: https://doi.org/10.21315/apjee2019.34.1

\begin{abstract}
This study investigated the current level of awareness on diversity-related issues and its relations to diversity climate and global-mindedness of students and lecturers in Malaysian Higher Education Institutions. A total of 615 students from various private and public universities, polytechnics and community colleges participated in the survey. They comprised Chinese, Malay, Indians and others. The Diversity Climate Survey and the Global Mindedness Scale by J. E. Hett were used and the analysis was conducted using ANOVA and Bivariate Correlational Analysis. The construct reliability for both tests ranged between .86 and .90 and .58 and .76 for Diversity Climate and Global Mindedness respectively. Results indicated that differences were found in the perceptions of diversity climate and levels of global mindedness in terms of gender, ethnicity and types of institution. Overall, the Malaysian Higher Education Institutions have reported a moderate climate in diversity and a low level of global-mindedness. In terms of ethnicity, there was a significant difference in students' perception of Diversity Climate and Global Mindedness. A broader scope of knowledge and awareness on learner diversity is needed to ensure sustainable development of our higher education institutions.
\end{abstract}

Keywords: learner diversity, diversity climate, global mindedness, higher education

(C) Penerbit Universiti Sains Malaysia, 2019. This work is licensed under the terms of the Creative Commons Attribution (CC BY) (http://creativecommons.org/licenses/by/4.0/). 


\section{INTRODUCTION}

The entry of globalisation movement in a society where a macrocosm of multicultural pathways exists, demands a transformative enlightenment of its future direction. The influx of foreign students has dramatically changed the local landscape of higher education institutions into a global village where international students along with their culturally unique values and beliefs have to contend with the existing social fabric of the country. The increasing number of students from different racial or ethnic background is considered as one of the important elements in having diversity on campus. Ideally, with an increase in racial and ethnic composition of campus population, it is stipulated that the global mindedness among the campus community will also increase as students learn to appreciate the uniqueness of other cultures and have the experience of learning with people from different cultural or ethnic groups in higher education. However, scholars in other parts of the world continuously speak out about the lack of diversity in higher education (Moses, 2011; Turner, 2013). They postulated that many institutional barriers remain and challenges persist. This line of researchers documented longstanding issues on lack of racial, gender and ethnic diversity among students, staff and faculty. People are still thinking only about their local community instead of the global concern. Low awareness on global concerns among members of the faculty needs to be enhanced as it can become a stepping stone for action and interaction in this particular context and it should not be treated as barriers (Hurtado, Milem, Clayton-Pederson, \& Allen, 1999).

\section{Problem Statement}

This changing scenario has created an educational value whereby students are being challenged on their ideas and arguments, forced to understand issues from different perspectives, reflect on their own actions and test their hypotheses against those of opposing views (Rudenstine, 2001). However, it is argued that the presence of students from diverse cultural backgrounds in a classroom does not only present itself as a challenging condition for learning, but it also gives rise to feelings of inferiority or superiority rather than promote growth and development.

Turner (2013) argues that issues on diversity practice in higher education still persist. Even in a multicultural setting like Malaysia, it becomes a challenge for most universities to increase diversity. Illuminating diversity practices means that more efforts need to be done to improve the situation. As pointed out by Gurin, Dey, Hurtado and Gurin (2002, p. 363), "In order to foster citizenship to a diverse democracy, educators must intentionally structure opportunities for students to leave the comfort of their homogeneous peer group and build relationships across 
racially or ethnically diverse student communities on campus". The increased presence of diverse learners demands richer and more fluid interactions and relationships. Although the curriculum, being the heart of instruction, expectedly propels lecturers to plan responsive programs enabling students' manifestation of desired learning experiences, they nevertheless ought to connect the formal curriculum with experiences students imbibe from non-formal, informal, and alternative settings, hence broadening the expanse of curricular content and activities.

While efforts have been made to increase diversity, scholars continue to write about the lack of diversity in higher education (Turner, 2013; Flores \& Rosa, 2015). Turner (2013) argues that longstanding challenges continue and that lack of racial, ethnic and gender diversity among students, faculty and staff remain intact. While diversity issue has become a major concern in many countries with diverse populations, very little research has examined the effect of diversity in the educational sector (Lauring \& Selmer, 2011). Taking this into account, we feel that there is an urgent need to address the issue of diversity in a multicultural context like Malaysia which practices multiculturalism. If this issue is not taken seriously it will lead to racial tension and will eventually threaten the stability and harmony of the country. Indirectly, it will also affect the country's economy with the lack of foreign investments due to social instability. Furthermore, diversity related issues are not widely studied and the level of awareness among teachers is often not addressed (Lauring \& Selmer, 2011). Abdul Razaq, Norhasni, Zalizan and Anisa (2011) who investigated teachers' perspectives toward school diversity among 161 teachers in Malaysia showed that the mean scores of teachers' perspectives were found to be average. This is unfortunate, because as student and staff movement increased, there is a demand for equal opportunity and the pressure to internationalise education in the context of higher education. In the context of Malaysian Higher Education, internalising process is done by embedding diversity elements into the curriculum which is done through series of training organised by the Higher Education Leadership Training Academy (AKEPT) (Awang-Hashim, Valdez-P, Tengku Ariffin, \& Yusof, 2015). Lauring and Selmer (2011) also claim that "very few studies deal with diversity in the education sector and hardly any focus on staff diversity" and that "while the number of diversity climate studies is rapidly growing, we are still in need to identify antecedents for a positive social climate in diverse organizations" (p. 349).

Responding to this gap, this paper aims to contribute to the literature on diversity in higher education particularly in a multicultural society like Malaysia. As diversity climate and global mindedness are vital in ensuring a healthy campus environment, there is an urgent need to address this issue. Higher education academics also need 
to develop a sense of awareness and understanding of what it takes to manage these culturally diverse classrooms in line with the Malaysian National Higher Education Strategic Plan (NHESP) 2007-2020) which aims at transforming the country into a regional education hub by 2020 (Abd Aziz, Siong, Tin, \& Abdullah, 2011). In view of the transformative movement globally and in the Malaysian education system particularly, this study investigated the current level of awareness on diversity and its relation to diversity climate and global mindedness of students and lecturers in the Malaysian Higher Education Institutions. It aims to examine the followings issues:

1. Students' and lecturers' perceptions of diversity climate and global mindedness.

2. Relationship between diversity climate and global mindedness of both students and lecturers.

3. Differences in perceptions of diversity climate and global mindedness in terms of gender, ethnicity, and type of institutions.

4. Issues and concerns on learner diversity.

However, as this is part of a larger project, this paper will only discuss the findings derived from the quantitative analysis which focuses on the students' and lecturers' perspectives of diversity climate and global mindedness.

\section{LITERATURE REVIEW}

\section{Related Studies on Diversity}

Diversity generally refers to differences in race, ethnicity, sex, religion, sexual orientation, gender identity, culture, cognitive and physical ability, age and nationality. Paine's (1989) diversity concept proposes four layers of meanings namely: individual, categorical, contextual, and pedagogical differences. Individual difference perspective draws on psychological (dispositions, interests, etc.) and biological explanations (sex, age, etc.) of diversity. Categorical difference considers gender, social class and race as salient attributes in understanding learner differences. Contextual difference exists in part because of the social context, while pedagogical difference considers causes and pedagogical implications. On the other hand, Shulman's (1986) conception of pedagogical content knowledge views diversity by combining understandings of human diversity with knowledge of and skills in ways to respond to or build on diversity in the educational settings. 
Earlier studies acknowledged that diversity plays an important role in students' learning (Kamuche, 2005; Shaw, 2005; Sulkowinski \& Deakin, 2009; Boland, Sugahara, Opdecam, \& Everaert, 2011; Nield, 2004). Sulkowinski and Deakin (2009) argue that cultural understanding enhances students' learning whereby there is an evidence of a positive correlation between culture and learning approaches. Another study on the impact of cultural factors on students' learning style preferences of 244 undergraduate students studying in Japan, Australia and Belgium conducted by Boland et al. (2011) discovered that the student groups from Australia and Belgium tended to be more individualistic in their learning and were more willing to learn by doing, while Japanese preferred learning by watching. In addition, Nield (2004) who investigated learning, teaching and assessment preferences of Chinese students discovered that Hong Kong Chinese students were rote learners who have certain preferences for certain methods of teaching and assessment, and have a different view of the role of the teacher. He concluded that learner differences need to be addressed by the lecturers if they intend to maximise their students' full potentials. Kamuche (2005) also provided empirical evidence that there was a very strong linear relationship between students' learning styles, instructors' teaching styles and students' test performance. Similarly, a case study of Dutch students also revealed that teacher performance influences student achievement and that this influence is more pronounced for non- western students (Middlekoop, Ballafkih, \& Meerman, 2017). Thus, lecturers not only need to be aware of the problems associated with diversity but also make necessary modifications to their teaching techniques to accommodate students of diverse backgrounds (Yusof, Awang-Hashim, Valdez, \& Yaacob, 2018). Insensitivity to these issues may lead to inequality subsequently undermine the potential learning that can occur among diverse peers. As such, mismatches in teaching and learning styles as a result of cultural diversity can adversely affect the learning outcomes.

\section{Conceptual Underpinnings}

\section{Diversity climate}

Diversity is the range of human differences, but not limited to race, ethnicity, gender, age, social class, physical attributes, religious or ethical values. It may include the mentality or perception of certain group of people, how they think, act based on the context that they are in. Hurtado et al.'s (1999) diversity climate model is employed as the framework which focuses on four dimensions such as historical legacy, structural, psychological and behavioural climate. Historical Legacy refers to the government's policy of inclusion and exclusion, while structural diversity concerns with the physical presence of previously underrepresented groups at a particular institution. This dimension is often considered when institutional leaders 
initiate diversity-related programs and policies on campus and such initiatives involve efforts to increase the diversity of students, staff and faculty.

Structural diversity is another important component of the campus climate, and scholars have found it to be related to minority students' perceptions of tension on campus and experiences with racism, as well as their academic adjustment to college (Hurtado et al., 1999). Structural diversity is however perceived as a catalyst in enhancing the opportunity for intergroup contact, which consequently has its impact on educational outcomes over time. A number of scholars have argued that although it is important to escalate the multitude of diversity, it is not sufficient to just create a more comfortable and less hostile environment for all (Gurin et al., 2002).

The psychological dimension on the other hand, is meant to capture the extent of individuals' views of group relations, institutional response to diversity, perceptions of discrimination or racial conflict, and attitudes held toward others from different racial or ethnic backgrounds. Hurtado et al. (1999) outlined the outcomes of exploring psychological climate and its influence, due to the fact that individuals experience campuses very differently, and this is especially accurate when applied to students of different racial and ethnic backgrounds. Often, the perceptions of a hostile climate can negatively influence student outcomes, particularly for students of colour. In addition, students' psychological distress and achievement have also been found to be the consequence of a hostile and discriminatory climate (Cress \& Ikeda, 2003). Behavioural dimension of the climate on the other hand, has been assessed using reports of interactions or contact experiences between and among different groups, for example, participation in campus programmes and diversity activities, and enrolment in diversity courses.

Although global perspective and diversity climate fall into different conceptual frameworks, both constructs are primarily framed to study the intergroup and global understanding and their relations, improve intercultural communication, reduce stereotyping and prejudice, and help people comprehend human diversity and human commonalities. Thus, it has been postulated that the improvement of global-mindedness of the lecturers may correlate with the increased positivity towards diversity issues in the classroom (Nilemar \& Brown, 2019) and thus, improve the quality of teaching and learning. Consequently, it is deemed crucial to examine the current level of awareness on diversity-related issues and its relations to the global-mindedness of students and lecturers in higher education in Malaysia. 


\section{Global mindedness}

An equally essential diversity construct used in the study which is global mindedness has been attributed as the foreground of developing an inclusive mindset and a broader world perspective. Global mindedness is significant in promoting the unity and interdependence of humankind, universal human rights, and loyalties that extend beyond national borders, and future-oriented perspectives. Hett (1993) defined global mindedness as a worldview in which one sees oneself as connected to the world community and feels a sense of responsibility for its members. Drawn from the same premise, five dimensions of global mindedness such as responsibility, cultural pluralism, efficacy, global centrism, and interconnectedness were constructed and is summarised in Table 1.

Table 1. Hett's (1993) dimensions of global mindedness

\begin{tabular}{|c|c|}
\hline $\begin{array}{l}\text { Dimension of global } \\
\text { mindedness }\end{array}$ & Description \\
\hline Responsibility & $\begin{array}{l}\text { A deep personal concern for people in all parts of the world, which } \\
\text { surfaces as a sense of moral responsibility to try to improve conditions } \\
\text { in some way. }\end{array}$ \\
\hline Cultural pluralism & $\begin{array}{l}\text { An appreciation of the diversity of cultures in the world, a belief that } \\
\text { all have something of value to offer accompanied by taking pleasure in } \\
\text { exploring and trying to understand other cultural frameworks. }\end{array}$ \\
\hline Efficacy & $\begin{array}{l}\text { A belief that an individual's actions can make a difference and that } \\
\text { involvement in national and international issues is important. }\end{array}$ \\
\hline Global centrism & $\begin{array}{l}\text { Thinking in terms of what is good for the global community, not } \\
\text { just what will benefit one's own country. It is a willingness to make } \\
\text { judgments based on global rather than ethnocentric standards. }\end{array}$ \\
\hline Interconnectedness & $\begin{array}{l}\text { An awareness and appreciation of the interrelatedness of all people and } \\
\text { nations resulting in a sense of global belongingness or kinship with the } \\
\text { human family. }\end{array}$ \\
\hline
\end{tabular}

\section{METHODOLOGY}

\section{Research Design}

The design involved a quantitative inquiry to address the objectives of this research. A survey method was employed to investigate the level of global-mindedness and respondents' perceptions toward diversity climate of both lecturers and students in higher education. This method of enquiry also analysed the relationships between the perceptions of diversity climate and the level of global-mindedness. 


\section{Sample and Data Collection}

A total of 615 students (190 male, 425 female) and 113 lecturers (33 male, 80 female) from various higher education institutions, including those from public and private universities, potytechnics and community colleges participated in this survey using a stratified random sampling method. Table 2 shows the profiles of the respondents.

Table 2. Profiles of the respondents $(N=728)$

\begin{tabular}{llcc}
\hline Variables & Category & Student & Lecturer \\
\hline Gender & Male & $190(30.9 \%)$ & $33(29.2 \%)$ \\
Types of institution & Female & $425(69.1 \%)$ & $80(70.8 \%)$ \\
& Public universities & $188(30.6 \%)$ & $40(35.4 \%)$ \\
& Private universities & $154(25.0 \%)$ & $17(15.0 \%)$ \\
& Polytechnic & $155(25.2 \%)$ & $29(25.7 \%)$ \\
Year of study & Community colleges & $118(19.2 \%)$ & $27(23.9 \%)$ \\
& 1st year & $264(42.9 \%)$ & - \\
2nd year & $95(15.4 \%)$ & - \\
Ethnicity & 3rd year & $133(21.6 \%)$ & - \\
& 4th year & $123(20.0 \%)$ & - \\
& Malay & $482(78.4 \%)$ & $84(74.3 \%)$ \\
& Chinese & $105(17.1 \%)$ & $19(16.8 \%)$ \\
& Indian & $15(2.4 \%)$ & $10(8.8 \%)$ \\
& Others & $13(2.1 \%)$ & - \\
\hline
\end{tabular}

As indicated in Table 2, $42.9 \%$ of the correspondent are 1st year students, $15.4 \%$ are 2 nd year students, $21.6 \%$ are 3 rd year students and $20 \%$ are 4 th year students. They are also came from various ethnic groups with the majority of Malay (78.4\%), followed by Chinese (17.1\%), Indian (2.4\%) and Others (2.1\%). Similarly, the majority of lecturers are Malay (74.3\%), followed by Chinese (16.8\%) and Indian $(8.8 \%)$.

\section{Instrument and Variables}

A survey consisting of 50 items was adapted from two established instruments: Diversity Climate Survey and the Global-Mindedness Scale (Hett, 1993). The Diversity Climate Survey was adapted from the University of Washington, 
consisted of 31 items that assessed participants' perceptions of their experiences both in and out of the classroom. This multidimensional construct is based on Hurtado et al.'s (1999) four dimensions of diversity climate: institution's history, structural diversity, psychological climate and behavioural climate. The construct is shaped by the policies, practices, and behaviours of those within and external to colleges and universities. The conceptualisation is constructed based on the perception that students are educated in distinct racial contexts where learning and socialising occur.

Students and lecturers' perceptions toward diversity climate were measured by self-ratings on a 31 items survey of four subscales described earlier. The ratings ranged from 1 (very strongly disagree) to 5 (very strongly agree). The 5-point Likert scale is being defined further as depicted in Table 3 .

Table 3. The 5-point Likert scale conversion to level

\begin{tabular}{lcc}
\hline Numerical scale & Weighted mean interval scale & Mean descriptive equivalent \\
\hline 5 & $4.21-5.00$ & Very high \\
4 & $3.41-4.20$ & High \\
3 & $2.61-3.40$ & Moderate \\
2 & $1.81-2.60$ & Low \\
1 & $1.00-1.80$ & Very Low \\
\hline
\end{tabular}

The Global Mindedness Survey measures participants' worldview in which they perceive themselves as connected to the world community and awareness of their responsibilities for the global community (Hett, 1993). This 21 items measure adapted from Hett (1993) assessed participants' perceived global mindedness through five domains/subscales: responsibility, cultural pluralism, efficacy, global centrism, and interconnectedness.

\section{Reliability and Validity}

Table 4 displays the summary of construct reliability of the instruments used in this study.

The reliability tests showed that for the diversity climate subscale, the values of the Cronbach alphas ranged between .86 and .90 and for the global mindedness subscale, the Cronbach alphas displayed the range between .58 and .76. Two items (one each from the dimensions of interconnectedness and cultural pluralism) had to be deleted from the scale due to low inter item to total correlation. Additionally, 
one dimension from global mindedness namely efficacy (which consisted of five items) had to be deleted due to low alpha value $(\alpha=.28)$. As a result, only four dimensions in global mindedness were examined. Overall, the results indicated that the test items were good.

Table 4. Summary of the construct reliability of the instruments

\begin{tabular}{|c|c|c|c|c|c|}
\hline Scale & No. of items & $\begin{array}{c}\text { Reliability } \\
\text { Alpha }(\alpha)\end{array}$ & Item mean & Min & Max \\
\hline \multicolumn{6}{|c|}{ A. Diversity climate (31 items) } \\
\hline Psychological & 13 & .89 & 3.67 & 3.24 & 3.89 \\
\hline Structural & 8 & .90 & 4.21 & 3.91 & 4.46 \\
\hline Historical legacy & 6 & .89 & 3.88 & 3.68 & 4.07 \\
\hline Historical policy & 4 & .86 & 3.93 & 3.76 & 4.07 \\
\hline \multicolumn{6}{|c|}{ B. Global mindedness (21 items) } \\
\hline Interconnectedness & 4 & .67 & 3.95 & 3.60 & 4.06 \\
\hline Global centrism & 5 & .58 & 2.26 & 2.06 & 2.57 \\
\hline Cultural pluralism & 7 & .76 & 3.92 & 3.56 & 4.24 \\
\hline Responsibility & 5 & .74 & 4.14 & 3.92 & 4.37 \\
\hline
\end{tabular}

Exploratory factor analysis (EFA) was run using Maximum Likelihood with Varimax rotation to test the factor structure of each of the scales. This was done to assess the construct validity of the instruments. Based on EFA conducted, two dimensions from diversity climate were loaded on one factor. As a result, the researchers decided to consider them as one construct namely psychological dimension. The results showed that EFA supported the two-factor structure solution namely: diversity climate and global mindedness. The total variance was found to be $60.6 \%$.

\section{RESULTS AND DISCUSSION}

Students' and lecturers' perceptions of diversity climate were analysed according to the four subscales described as the historical legacy and policy, the structural diversity (diverse students, faculty and staff), and the psychological and behavioural dimensions (perceptions of racial and interactions with diverse groups) (Hurtado et al., 1999). 


\section{Diversity Climate}

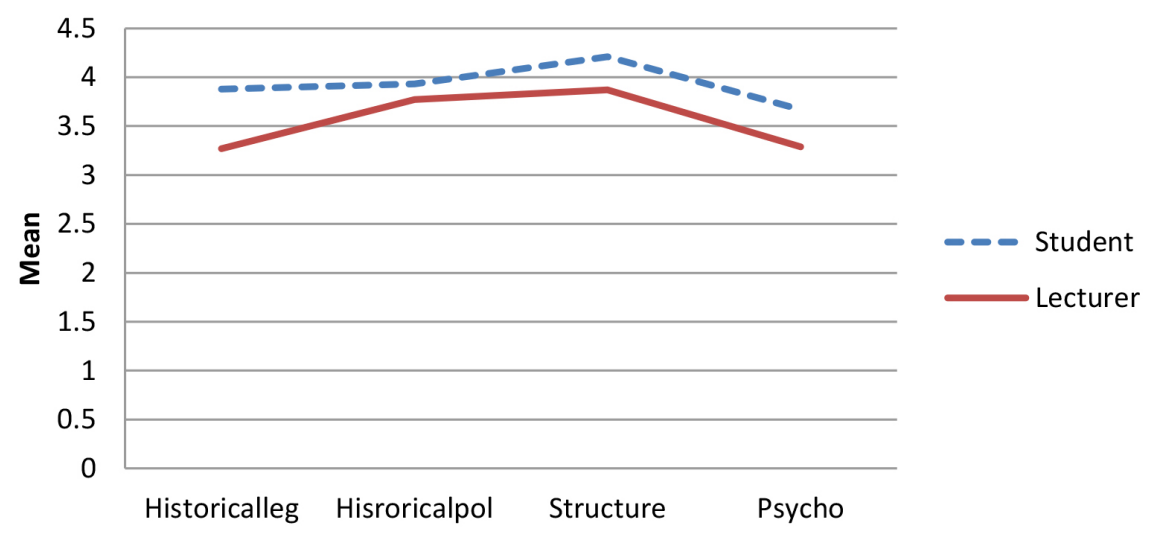

Figure 1. Diversity climate in higher education

Figure 1 shows the lecturers and students' perceptions of diversity climate in Higher Education. The results showed that the means for students in different dimensions are as follows: historical legacy $(\mathrm{M}=3.88, \mathrm{SD}=.69)$, historical policy $(\mathrm{M}=3.93, \mathrm{SD}=.65)$, structural $(\mathrm{M}=4.21, \mathrm{SD}=.65)$ and psychological dimension $(\mathrm{M}=3.67, \mathrm{SD}=.58)$. Students' perceptions of diversity climate for all dimensions were found to be high. Interestingly, a slightly different picture is displayed for lecturers' diversity climate. The means for lecturers in all dimensions are as follows: historical legacy $(\mathrm{M}=3.27, \mathrm{SD}=.86)$, historical policy $(\mathrm{M}=3.77, \mathrm{SD}=.82)$, structural $(\mathrm{M}=3.87, \mathrm{SD}=.90)$ and psychological dimension $(\mathrm{M}=3.29, \mathrm{SD}=.67)$. Lecturers' perceptions on institutional policy regarding recruitment and retention efforts and their perspectives on psychological and behavioural dimensions were found to be moderate. The lecturers were also concerned over the university's policies which did not incorporate learner diversity, inadequate conducive facilities, restrictive curriculum and the students' psychological dimensions which were raised in the focus group discussion. In addition, the lecturers' perspectives on the psychological and behavioural dimensions were also found to be moderate. This has brought to our understanding that although lecturers perceived positive attitude toward racial integration and welcome interactions with diverse groups in their institution, they viewed diversity as irrelevant. Similar findings were reported in other studies which claimed that some of the lecturers viewed diversity as irrelevant in the context of their teaching although some of them utilised diversity as an essential resource in their teaching (Gordon, Reid, \& Petocz, 2010). Kaur (2014) reinforced the importance of aligning students'cultural traits in conducting learner empowerment strategies in the learning English in the Malaysian setting. 


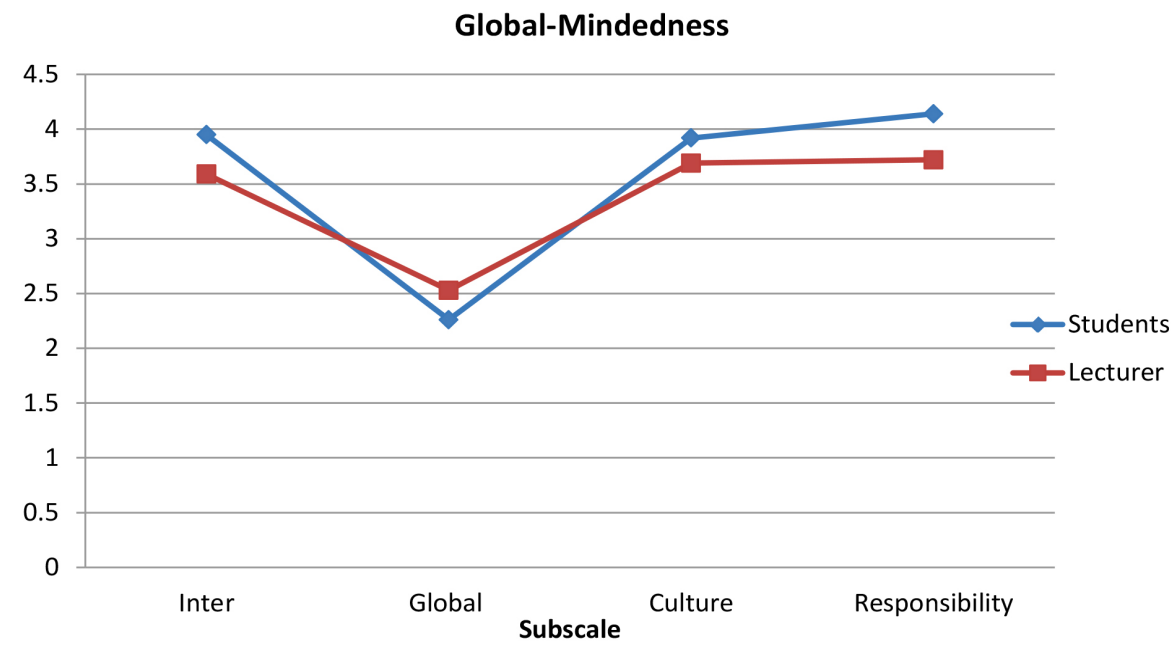

Figure 2. Level of global-mindedness

Figure 2 shows the lecturers and students' perceptions of global mindedness. For students, the means for different dimensions are as follows: interconnectedness ( $\mathrm{M}$ $=3.95, \mathrm{SD}=.58)$, global centrism $(\mathrm{M}=2.26, \mathrm{SD}=.58)$, culture pluralism $(\mathrm{M}=$ $3.92, \mathrm{SD}=.56)$ and responsibility $(\mathrm{M}=4.14, \mathrm{SD}=.58)$. For lecturers, the findings are: interconnectedness $(\mathrm{M}=3.59, \mathrm{SD}=.69)$, global centrism $(\mathrm{M}=2.53, \mathrm{SD}=$ $.63)$, culture pluralism $(\mathrm{M}=3.69, \mathrm{SD}=.66)$ and responsibility $(\mathrm{M}=3.72, \mathrm{SD}=$ .74). The results revealed that the level of global-mindedness for both students and lecturers was high for all dimensions except for the dimension of global centrism which was low.

This study revealed that the level of global-mindedness for both students and lecturers were high for all dimensions except for the dimension of global centrism. Hett's (1993) global centrism means thinking in terms of what is good for the global community. Both students and lecturers rated their thinking of what is good for the global community as low. This is quite alarming as it shows their lack of concern for the global community. Deep concern about other people from the other part of the world and the sense of moral responsibility to serve the global community seemed to be absent in a multicultural context like this study. This makes one wonder whether diversity creates wider barriers in higher education. Our finding is in line with earlier studies that reported the lack of global concern or global thinking in universities. Some argued that universities aimed to educate global citizens show limited outcomes (Lilley, Barker, \& Harris, 2015, 2016; Paige $\&$ Mestenhauser, 1999). Lilley et al. (2016) suggested for a clearer definition of global citizenship and internationalisation. 
Pearson correlations conducted for the two main variables in the study showed that there was a significant relationship between perceived global mindedness and diversity climate for both lecturers $(r=.63, p<0.05)$ and students $(r=.58$, $p<0.05)$. The correlation of both constructs suggests that students and lecturers who demonstrated higher level perspectives on diversity climate also tended to have higher levels of global-mindedness. This finding confirms Acolaste (2010) and Zhai and Scheer's (2004) assertion that there was a correlation between attitudes toward diversity and global perspectives among students. Students with a higher level of global perspectives tend to have a more positive attitude toward cultural diversity (Zhai \& Scheer, 2004).

In terms of ethnicity, there was a significant difference in students' perception ( $\mathrm{F}$ $(3,615)=5.87, p<.001)$ of the diversity climate, whereas there was no significant difference found among lecturers in this dimension. Results also indicated that in terms of ethnicity, there was a significant difference found in the level of globalmindedness for both students $(\mathrm{F}(3,615)=7.26, p<.001)$ and lecturers $(\mathrm{F}(2,113)$ $=4.31, p<.001)$.

\section{IMPLICATIONS AND CONCLUSION}

For today's practitioners, using the multi-cultural lens is not just a matter of choice, but it is a matter of survival. The changing composition of the academic community signals the continuous effort of building-up the tacit knowledge and repositioning the mindsets of the academics. In this piece of work, the acquisition and display of a broad-based world view or global-mindedness needs to be strongly explored. This study calls for more attention from the government particularly higher education institutions to intervene in diversity issue and provide functional mechanisms that trigger initiatives of stakeholders to address the quality of education which includes inclusion of learner diversity and global mindedness. In addition, given the backdrop of a multicultural society, systemic practices demand that institutional mandates, policies and guidelines to include the sensitivities of inclusive practice. Only when these governing policies are understood and utilised, the inflow of rich and valuable inputs from diverse perspectives manage to fillin diversity gaps and barriers. If these elements are not present in the campus environment, diversity practices may not be achieved.

Our findings can be used to change the diversity climate not just in terms of racial interrelationship but also in terms of the mindset of the people which could contribute to the diversity climate of the university. Lack of global mindset among the campus community is alarming as they are the main agent of change 
or transformation. This mindset has to be changed and it should receive greater attention in future studies.

In conclusion, we recommend that higher education institutions to infuse into existing operational policies and acceptable practices that work against the principles of diversity and to develop a comprehensive diversity awareness platform such as mandated development and training along with other campaign modalities to intensify the application and practice of diversity learning of staff, students and teachers in the real-world or workplace contexts (PadillaValdez, Awang-Hashim, \& Miguel-Aclan, 2017). We also recommend that the institutional support service providers to diversify functions and activities that provide connectivity, ensure collaboration, and facilitate respect among students and lecturers. This is bound to be necessary to sustain diversity in the workplace contexts. It has been argued that there was an absence of template for interaction across racial and ethnic groups (Gurin et al., 2002). More attention need to be given to the types of experiences students have with their peers inside and outside the classrooms. At the instructional level, learner diversity can be introduced into the broad curriculum by incorporating inclusive-driven strategies while making instruction, learning and evaluation more pedagogically sound for all students. As such, more diversity training for lecturers, staff and students is also needed not only to expose them to various teaching methods and approaches but also to provide avenues for discussion on managing and sustaining diversity.

\section{ACKNOWLEDGEMENTS}

This work was funded by the Higher Education Leadership Training Academy (AKEPT), Ministry of Higher Education Malaysia (S/O Code: 12993).

\section{REFERENCES}

Abd Aziz, M. I., Siong, H. C., Tin, L. C., \& Abdullah, D. (2011). Measuring impact of internationalization on Malaysian higher education. Paper presented at the Global Higher Education Forum in Universiti Sains Malaysia. Retrieved 19 September 2012, from https://www.gheforum.usm.my

Abdul Razaq Ahmad, Norhasni Zainal Abidin, Zalizan Mohd Jelas, \& Anisa Saleha. (2011). Teachers' perspectives toward schools diversity. International Journal of Business and Social Science, 2(4), 178-189.

Acolaste, R. T. (2010). Globalmindedness and dispositions towards diversity in the classroom. Unpublished doctoral dissertation, West Virginia University. 
Awang-Hashim, R., Valdez-P, N., Tengku Ariffin, T. A., \& Yusof, N. (2015). Lead initiatives on teaching and learning in Malaysian higher education institutions. In K. Ab. Hamid et al. (Eds.), The Malaysian-Japan Model on Technology Partnership: International Proceedings 2013 of Malaysia-Japan Academic Scholar Conference (pp. 415-418). Japan: Springer. https://doi.org/10.1007/9784-431-54439-5 42

Boland, G., Sugahara, S., Opdecam, E., \& Everaert, P. (2011). The impact of cultural factors on students' learning style preferences: A global comparison between Japan, Australia and Belgium. Asian Review of Accounting, 1(3), 243-265. https://doi.org/10.1108/13217341111185155

Cress, C. M., \& Ikeda, E. K. (2003). Distress under duress: The relationship between campus climate and depression in Asian American college students. NASPA Journal, 40, 74-97. https://doi.org/10.2202/0027-6014.1224

Flores, N., \& Rosa, J. (2015). Undoing appropriateness: Raciolinguistic ideologies and language diversity in education. Harvard Educational Review, 85(2), 149-171. https://doi.org/10.17763/0017-8055.85.2.149

Gordon, S., Reid, A., \& Petocz, P. (2010). Educators' conceptions of student diversity in their classes. Studies in Higher Education, 35(8), 961-974. https://doi. org/10.1080/03075070903414305

Gurin, P., Dey, E. L., Hurtado, S., \& Gurin, S. (2002). Diversity and higher education: Theory and impact on educational outcomes. Harvard Educational Review, 72(3), 330-366. https://doi.org/10.17763/haer.72.3.01151786u134n051

Hett, J. E. (1993). The development of an instrument to measure global-mindedness. Unpublished doctoral dissertation, University of San Diego.

Hurtado, S., Milem, J., Clayton-Pederson, A., \& Allen, W. (1999). Enacting diverse learning environments: Improving the climate for racial/ ethnic diversity in higher education (Vol. 26). Washington, DC: Graduate School of Education and Human Development, The George Washington University.

Kamuche, F. (2005). Do learning and teaching styles affect students' performance? An empirical study. Journal of Business \& Economics Research, 3(9), 35-40. https:// doi.org/10.19030/jber.v3i9.2806

Kaur, N. (2014). Teacher-led initiatives in supporting learner empowerment mong Malay tertiary learners. Malaysian Journal of Learning and Instruction, 11(1), 101-126.

Lauring, J., \& Selmer, J. (2011). Social climate in diverse university departments: The role of internal knowledge sharing. Educational Research, 53(3), 347-362. https://doi. org/10.1080/00131881.2011.598662

Lilley, K., Barker, M., \& Harris, N. (2015). Exploring the process of global citizenship learning and the student mind-set. Journal of Studies in International Education, 19(3), 225-245. https://doi.org/10.1177/1028315314547822

Lilley, K., Barker, M., \& Harris, N. (2016). The global citizen conceptualized: Accommodating ambiguity. Journal of Studies in International Education, 21(1), 6-21. https://doi.org/10.1177/1028315316637354 
Middlekoop, D. V., Ballafkih, H., \& Meerman, M. (2017). Understanding diversity: A Dutch case study on teachers' attitudes towards their diverse student population. Empirical Research in Vocational Education and Training, 9, Article 1. Retrieved from https://ervet-journal.springeropen.com/articles/10.1186/s40461-016-0045-9

Moses, Y. T. (2011). Black women in academe: Twenty-two years later. On campus with women: Forty years of the program on the status and education of women, 39. Washington DC: American Association of Colleges and Universities. Retrieved from https://www.aacu.org/ocww/volume39_3/feature.cfm?section=3

Nield, K. (2004). Questioning the myth of the Chinese learner. International Journal of Contemporary Hospitality Management, 16(3), 189-196. https://doi. org/10.1108/09596110410531186

Nilemar, K., \& Brown, L. (2019). Academic mobility and cultural change. Journal of Further and Higher Education, 43(1), 89-100.

Padilla-Valdez, N., Awang-Hashim, R., \& Miguel-Aclan, E. (2017). Repositioning the inclusive perspectives in globalized schools through advocacy optimization of reflective practitioners. In I. Amzat, \& N. Padilla-Valdez (Eds.), Teacher professional knowledge and development (pp. 214-236). New York: Routledge. https://doi.org/10.4324/9781315397702-19

Paige, R. M., \& Mestenhauser, J. A. (1999). Internalizing educational administration. Educational Administration Quarterly, 35(4), 500-517. https://doi. org/10.1177/0013161X99354005

Paine, L. (1989). Orientation towards diversity: What do prospective teachers bring? Retrieved from https://ncrtl.msu.edu/reports/html/pdf/rr899.pdf

Rudenstine, N. L. (2001). Student diversity and higher learning. In G. Orfield (Ed.). Diversity challenged: Evidence on the impact of affirmative action (pp. 31-48). Cambridge: Harvard Education Publishing Group.

Shaw, E. J. (2015). Researching the educational benefits of diversity. New York: College Board Publications.

Shulman, L. S. (1986). Those who understand knowledge growth in teaching. Educational Researcher, 15(2), 4-14. https://doi.org/10.3102/0013189X015002004

Sulkowinski, N. B., \& Deakin, M. K. (2009). Does understanding culture help enhance students' learning experience? International Journal of Contemporary Hospitality Management, 21(2), 154-166. https://doi.org/10.1108/09596110910935651

Turner, C. S. (2013). Advancing diversity in higher education. Journal of Diversity in Higher Education, 6(3),155-157. https://doi.org/10.1037/a0034356

Yusof, N., Awang-Hashim, R., Valdez, N. P., \& Yaacob, A. (2018). Managing diversity in higher education: A strategic communication approach. Journal of Asian Pacific Communication, 28(1), 41-60. https://doi.org/10.1075/japc.00003.yus

Zhai, L., \& Scheer, S. D. (2004). Global perspectives and attitudes toward cultural diversity among summer agricultural students at the Ohio State University. Journal of Agricultural Education, 45(2), 39-51. https://doi.org/10.5032/jae.2004.02039 